\title{
https://doi.org/10.48009/1_iis_2005_80-86 \\ CONNECTING STUDENTS AND FACULTY TO BUSINESS: THE PIPES PROJECT
}

\author{
Steven C. Ross, steve.ross@wwu.edu, Craig K. Tyran, craig.tyran@wwu.edu, \\ Kristi L. Tyran, kristi.tyran@wwu.edu, Thomas Roehl, tom.roehl@wwu.edu, \\ John Sands, john.sands@wwu.edu, Western Washington University
}

\begin{abstract}
This paper describes the planning and requirements definition phases of a project being developed by a collegiate school of business. The systems analysts were asked to design a system that would record information about many types of industry contacts with the university - ranging from guest speakers to mentors to internships to advisory board memberships. Complicating the design was the requirement that some information be made public while access to other information be restricted to only a few individuals or groups. At the time the paper was written, the project had reached a feasibility checkpoint: considering whether to proceed into the design phase. This paper contains system description and justification, scope statement, data requirements, a preliminary data model, and an analysis of the user interface and major subsystems.
\end{abstract}

Keywords: systems development, mentor, internship, industry contact, confidentiality

\section{INTRODUCTION}

Professional degree programs value contact with business and government organizations through mechanisms such as internships, field projects, advisory boards, and guest speakers. For example, experiential learning projects such as internships and field projects can provide significant learning benefits for students [e.g., 3. 6]. The management of the projects and contacts necessary for a successful program can place a heavy burden on faculty. This paper discusses technical and organizational issues associated with the design of a system that supports faculty who use fieldbased learning by providing a secure and easy-to-use way to record, manage, and share information. In addition to an internal requirements analysis, published information regarding systems such as generic "contact management systems" [e.g., 5] and "knowledge management systems" [e.g., 4] was examined to identify useful features for such a system. The name of the proposed system is the Partners in Professional Education System (PIPES). This name reflects the fact that field-based learning is a partnership among faculty, students, and industry participants.

\section{PROJECT MOTIVATION}

\section{Support for Faculty and College Administration}

The College of Business and Economics has developed an increasing number of contacts with the business community, such as programs for student internships, class speakers, alumni relationships and financial support. This has been the result of entrepreneurial activities on the part of individual faculty members rather than a centralized policy for the school as a whole. As business contacts have become a more important element of the program activity of the College, however, better information exchange between the programs and some coordination of activity has become more important. Although faculty often view these individual programs as somewhat independent, the business community expects to see a coordinated program from our College. 
Some form of "knowledge management system" [e.g., 1] to allow faculty to share information and ideas is needed.

We also find that the individual programs and contacts are increasingly overlapping. When multiple contact points coexist, two serious problems exist. First, the College does not know how to combine various relationships to take full advantage of the opportunities. Second, some faculty members may feel that someone is taking advantage of the relationships they have developed, and that the other contacts, which they don't "control," might damage the existing relationship. Much of the tracking of the individual relationships is not well structured, so that the history and experience may not be available when there are personnel changes and when people want to assess the potential of particular projects.

One professor stated his expectations for the PIPES system as follows: "As I prepare for my Entrepreneurial Problems class, I find that I have more projects than I have students. PIPES can be a way to steer those extra projects to other faculty. In another class, we involve business executives as judges of business plan presentations. PIPES would be a valuable recruiting tool. On the other hand, we must guard against burn out of our industry partners. PIPES could provide a count of an individual's activities to help us spread the work we ask of our business contacts. PIPES can serve faculty, students, and industry partners by providing information on who is doing what type of project, event or on-going activities."

From the perspective of the College's administration, an additional consideration is the requirement to document, for accreditation purposes and for possible financial contributions, the history of the relationships with business contacts. An improved system for coordinating the College's activities may provide benefits in the area of customer relationship management, as it applies to the various CBE stakeholders [2].

\section{Support for Students}

Students understand the value of exposure to and experience with business and seek out opportunities to interact with business professionals throughout their academic programs. PIPES will provide a convenient conduit to information about opportunities to interact with industry. For example, if a student is interested in an internship, he or she can see what courses and concentrations have internship requirements or opportunities. A student who wants team consulting experiences can find classes that provide these opportunities as well as information on the specific projects. Finally, the student who wants a more personal, one-on-one relationship with a business professional can see where there are opportunities for mentoring or interacting with visitors who speak in class, to clubs, or to the broader college community.

\section{Support for Industry Partners}

Industry professionals are frequently asked to participate in a variety of College activities. The College depends on busy professionals for insights into the world of business and for assistance with respect to activities such as field-based learning projects, speaking engagements, and student mentoring. Business people often ask us for examples of past student projects or examples of what other industry professionals have done so that they may get a better idea of how they can help and how their efforts will benefit students. Preparation of this type of information can be very time-consuming. PIPES will be designed to provide this information directly to industry 
partners in a quick and user-friendly way. PIPES will showcase the College's extensive involvement with industry and provide participating businesses with a sense of being a part of an exclusive "club" of organizations involved in higher education.

\section{Confidentiality Concerns}

An important design challenge that emerged during initial interviews concerned access to information. Faculty work hard to nurture and develop relationships with industry partners who participate in field-based projects. There is a concern that such relationships could be poached or damaged if others had access to too much information. Since this system will be used by a variety of people, it must be crafted so that different people will have access to different parts of the system. Decisions will have to made on the degree of information to provide, as well as who has access to elements of the data base at all. We must also protect proprietary information that organizations might have shared with students and/or faculty during the course of a given project.

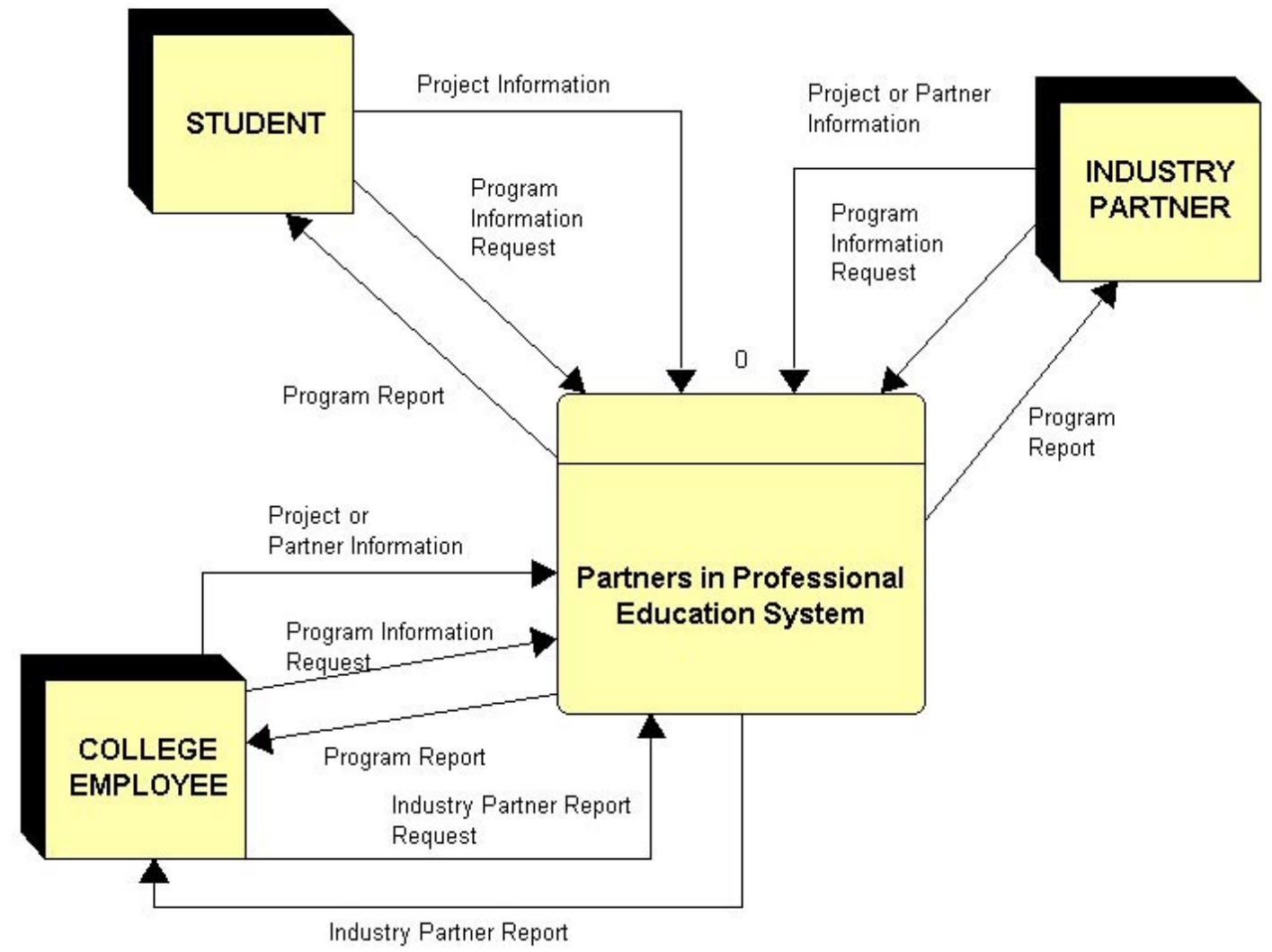

Figure 1. Context Diagram

\section{PROJECT SCOPE}

Figure 1 provides a context diagram to illustrate the scope of PIPES and the external entities that will be interfacing with the system. As indicated in this diagram, the three external entities are all the partners in professional education for our College: the employees of the College [e.g., faculty, administration), the students, and the industry partners. As suggested by the diagram, the system will provide the following capabilities: 
- Will enable individual faculty members to easily store and update information about their programs (e.g., specific field-based project information, guest speakers, etc.).

- Will provide all stake holders (employees, students, and industry partners) with an easy to use means of generating reports concerning the different programs within the College. (Note: The information in a report will depend on the stake holder's level of access.)

- Will allow members of the College to better coordinate relationships with industry partners by means of a knowledge management system regarding industry partners.

\section{SYSTEMS REQUIREMENTS}

Space limitations preclude an exhaustive description of the requirements. In this section, we highlight the major elements of the data model, the design to assure proper handling of confidential items, and process and user interface design.

\section{Data Model}

The system is designed to interface with the university database for information about students, faculty, and class sections. The major entities are described below. UNDERSCORED entities are from the University database. See Figure 2 for a simplified entity-relationship diagram.

- ORGANIZATION: business or other type of organization other than the university - organizations sponsor programs and events, contain org_persons.

- ORG_PERSON: "organization" (non-university) person - org_persons participate in programs and events and may have one or more relationships with the university (roles in addition to those defined vis-à-vis an event or program).

- UNIV PERSON: "university" person (faculty, student, staff) - a supertype with FACULTY and STUDENT subtypes; univ_persons participate in programs and events, are related to classes, and write reports; faculty univ_persons advise programs and coordinate events.

- PROGRAM: an on-going activity such as an advisory board, guest lecture series, mentoring panel, student organization - programs have univ_person and org_person participants

- EVENT: a one-time or defined term activity such as an internship, mentor, guest lecture events have univ_person and org_person participants; some events are directly related to classes; some events are affiliated with a program.

- $\quad$ CLASS: a specific (by term, number) section of a course - classes are taught by faculty and taken by students.

- REPORT: a narrative written by a univ_person about an event.

- RESTRICTION: records the rules imposed by owner (org_person or univ_person) and endorser (faculty).

\section{Design for Confidentiality}

This project poses some unique confidentiality requirements. Some restrictions vary from entity to entity: on one hand, only university faculty are able to see who is enrolled in a class and thus partakes in a class event; on the other hand, the College web site will provide public lists of all the various programs (but not participants). Other restrictions vary from record to record within same entity: details of an event such as a public speech may be available on the College web site while details of a Marketing internship (another type of event) may be limited to Marketing faculty and students. 


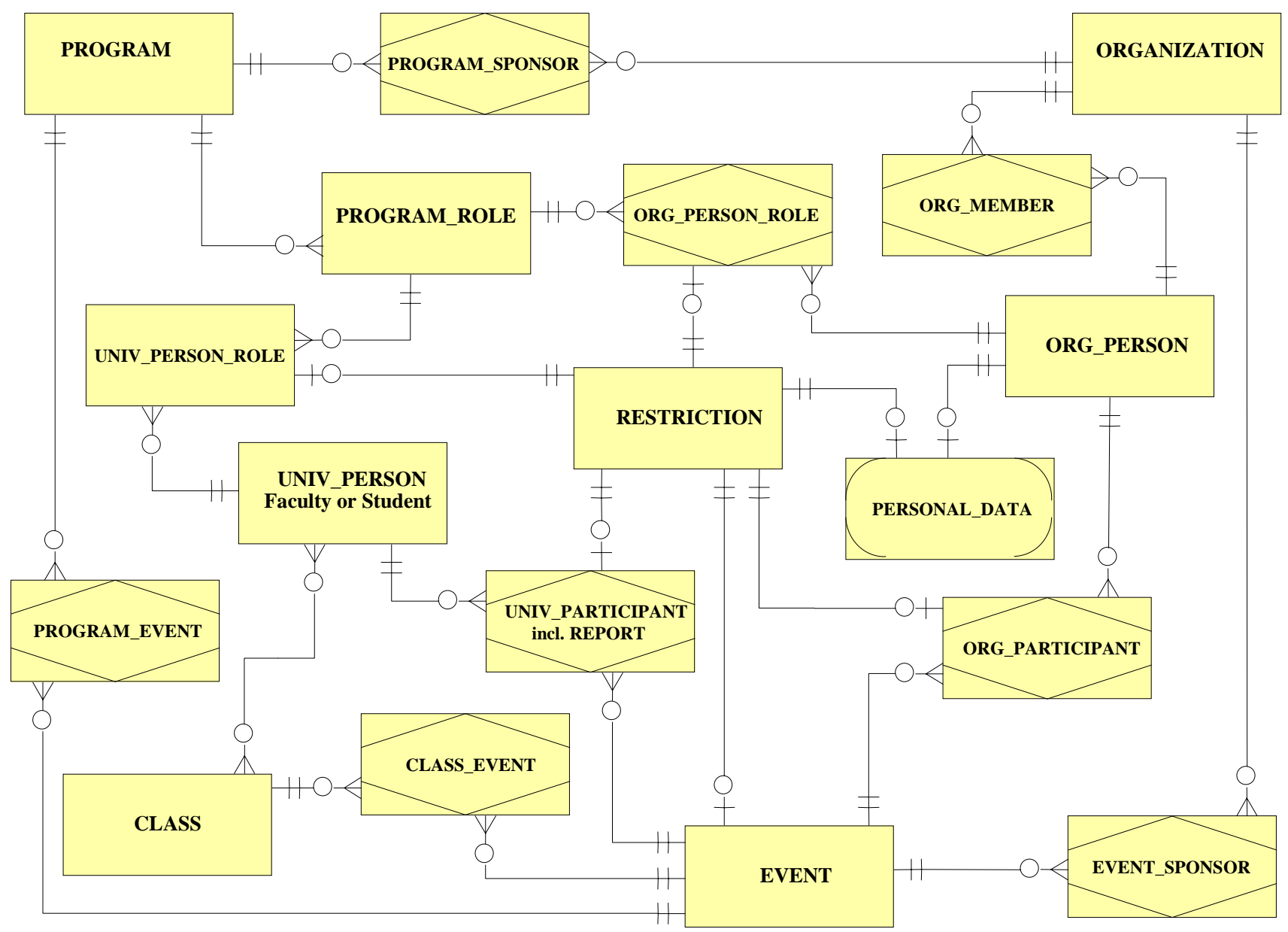

Figure 2. Entity-Relationship Diagram

The various limitations are recorded in an aggregate type entity named RESTRICTION, which contains Boolean fields such as AllowPublic, AllowCollFaculty, AllowCollStudent, AllowMajor, and AllowProgRole. It also contains fields that specify which college, major, or program role is allowed. Thus, a Marketing internship might have AllowMajor = true and MajorCode $=$ MKTG. Another internship might have no restrictions applied, thus the value of AllowPublic $=$ true. RESTRICTION is related to several entities. Restrictions can be applied to records of participation in a program or event, event descriptive data, personal data, relationship of ORG_PERSON to the university, and reports written by UNIV_PERSONs.

\section{Process and User Interface Design}

A process model for PIPES is shown in Figure 3. As indicated, there are four primary processes. The first addresses the data entry aspects of the system. The second and third processes concern the generation of reports. The fourth process addresses the confidentiality concerns. All user access to the system will be handled through a WWW-based interface that will be accessible through the Internet. While some features of the system will be open for public use (e.g., basic reports regarding field-based learning projects at the College), other features of the system such as data entry and restricted reports will require a user log-in and appropriate authorization. 


\section{PROJECT PLAN}

At the time this paper is written (May, 2005), the College administration has given approval and provided support for the development of a prototype system. Through summer and into fall of this year, the project team will undertake the following tasks:

- Complete logical design: database structure, user input forms, output forms and reports

- Create physical database structure, including interfaces with other systems

- Develop views and procedures to enforce the confidentiality requirements

- Populate database with sufficient data to allow interface development and testing

- Develop and test data input forms

- Design output forms and reports

At the completion of that work, the College will decide whether to continue work on its own, turn the system over to the university for wide-spread adoption, or terminate the project. Influencing the decision will be factors such as the ease of data entry and specification of restrictions, any unresolved issues in the data or process model, and a survey of the intended user base (faculty, students, and industry partners) to determine their willingness to populate the database.

\section{CONCLUSION}

Contacts with business organizations and business persons provide a valuable supplement to the educational experience of business students. Managing those contacts and sharing information among faculty, students, and the contacts themselves can be a daunting challenge in the absence of a system to record and report that information. The first steps in any such project are the definition of the scope of the system and delineating the system requirements.

In this project, the project team has developed a statement of the system scope and captured that in a context diagram. They have developed a preliminary data model that indicates the primary entities of interest and the relationships among those entities. An important part of that data model and future development tasks are the features to assure confidentiality of information. And, they have completed a level-0 model, delineating the primary processes of the system. 


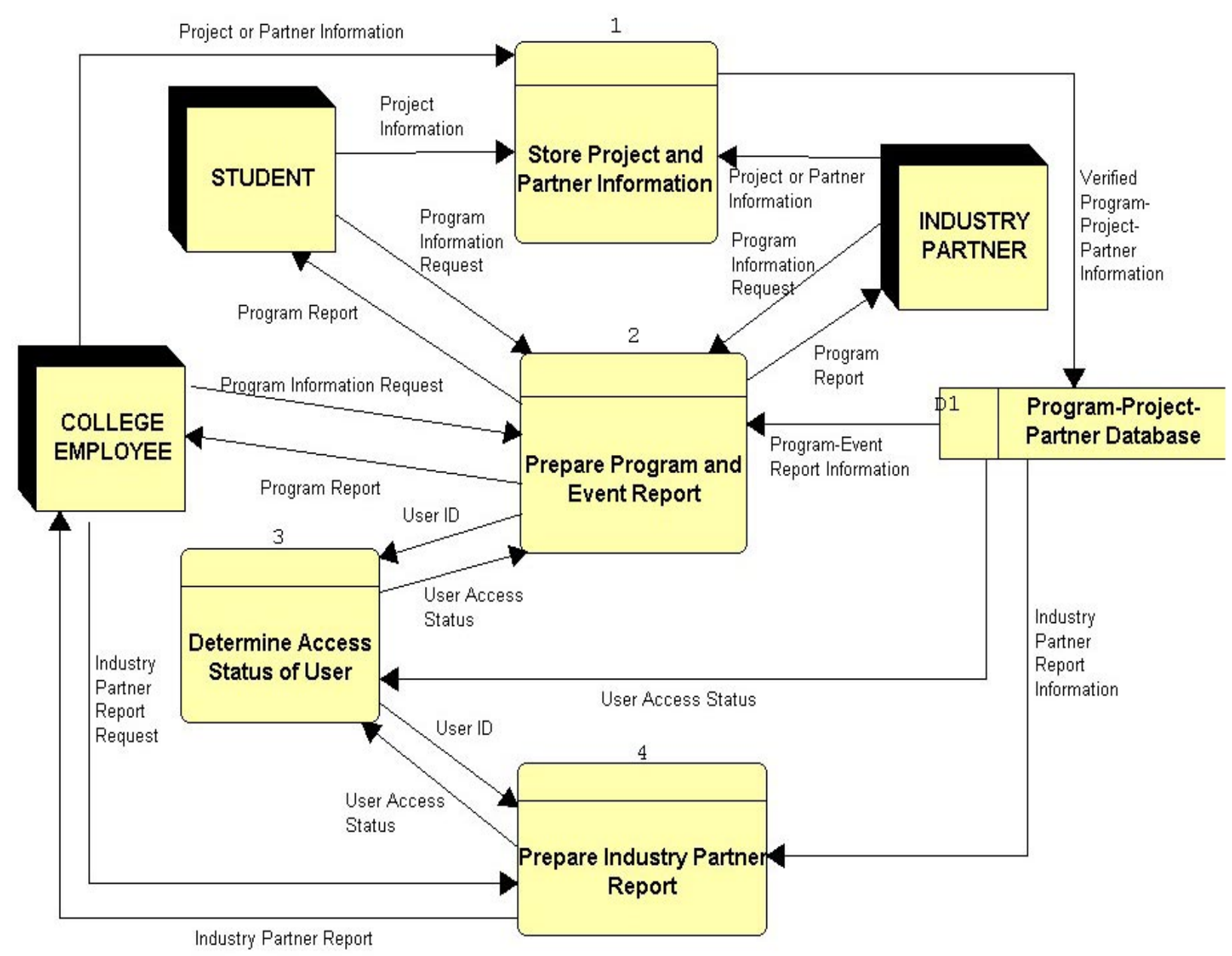

Figure 3. Level 0 Data Flow Diagram

\section{REFERENCES}

1. Davenport, T. (1998). Working Knowledge: How Organizations Manage What They Know. Boston, MA: Harvard Business School Press.

2. Grant, G.B. \& Anderson, G. (2002) Customer Relationship Management: A Vision for Higher Education. In R.N. Katz and Associates, (Eds.), Web Portals and Higher Education. (pp. 23-32). San Francisco: Jossey-Bass.

3. Kolb, D. (1984). Experiential Learning: Experience as the Source of Learning and Development. Englewood Cliffs, N.J.: Prentice-Hall.

4. Luan, J. \& Serban, A.M. (2002) Technologies, Models, and Products Supporting Product Management. New Directions for Institutional Research, 113, 85-104.

5. Miller, M. (1998). A Contact Database using MySQL and PHP. Web Techniques, 3(1), 63-67.

6. Quay, J. (2003). Experience and Participation: Relating Theories to Learning. Journal of Experiential Education, 26(2), 105-116. 